\title{
Educação a Distância, Sala de Aula Invertida e Aprendizagem Baseada em Problemas: possibilidades para o ensino de programação de computadores
}

\section{Sidnei Renato Silveira ${ }^{1}$, Adriana Soares Pereira ${ }^{2}$, Cristiano Bertolini ${ }^{3}$, Fábio José Parreira $^{4}$, Nara Martini Bigolin 5}

Departamento de Tecnologia da Informação - Universidade Federal de Santa Maria Campus Frederico Westphalen - RS (UFSM/FW) Caixa Postal 54 - CEP 98400-000 - Frederico Westphalen - RS - Brazil

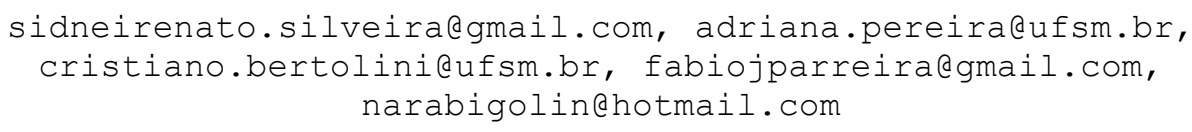

Resumo. Este artigo apresenta uma proposta de aplicação da Sala de Aula Invertida nas aulas de cursos superiores de Computação, especialmente nas disciplinas que envolvem Lógica de Programação e Programação de Computadores na modalidade de Educação a Distância. Tendo-se em vista a necessidade de que os processos de ensino e de aprendizagem sejam mais ativos, a metodologia da sala de aula invertida, aliada à Aprendizagem Baseada em Problemas, pode trazer beneficios aos alunos e professores, estimulando os alunos a construírem o conhecimento $e$ a aprenderem a aprender.

Palavras-Chave: Sala de Aula Invertida, Lógica de Programação, Educação a Distância

\begin{abstract}
This paper presents a proposal to applied Flipped Classroom in Computer Science Courses, focuses on classes about logic and computer programming in distance education. Based on that the learning and teaching processes must be more actives, the flipped classroom methodology, in collaboration with problem-based learning, can bring benefits to students and teachers, encourage the students to build the acknowledgment and learning how to learn.
\end{abstract}

Keywords: Flipped Classroom, Programming Logic, Distance Education

\footnotetext{
${ }^{1}$ Professor Adjunto do Departamento de Tecnologia da Informação da UFSM/FW. Doutor em Ciência da Computação pela UFRGS

${ }^{2}$ Professora Associada do Departamento de Tecnologia da Informação da UFSM/FW. Doutora em Ciência da Computação pela UFRGS

${ }^{3}$ Professor Adjunto do Departamento de Tecnologia da Informação da UFSM/FW. Doutor em Ciência da Computação pela UFPE

${ }^{4}$ Professor Associado Departamento de Tecnologia da Informação da UFSM/FW. Doutor em Engenharia Elétrica pela UFU

${ }_{5}^{5}$ Professora Associada do Departamento de Tecnologia da Informação da UFSM/FW. Doutora em Ciência da Computação pela UFRGS
} 
VII Congresso Brasileiro de Informática na Educação (CBIE 2018)

Anais dos Workshops do VII Congresso Brasileiro de Informática na Educação (WCBIE 2018)

\section{Introdução}

A Sala de Aula Invertida - ou Flipped Classroom - é uma metodologia ativa, que visa explorar menos aulas expositivas como ferramenta utilizada nos processos de ensino e de aprendizagem. Segundo esta metodologia, os alunos devem estudar os conteúdos em casa e irem à escola ou universidade para encontrar professores e colegas para esclarecer dúvidas, fazer exercícios, trabalhos em grupo e avaliações. Os encontros presenciais podem ser utilizados, também, para fortalecer a relação entre os estudantes e entre os estudantes e o professor. Nesta proposta, a "lição de casa" é feita em sala de aula e a aula é "dada em casa". Esta metodologia tem sido empregada em inúmeras universidades, tais como Harvard, Yale e Stanford, entre outras (ESCOLA DA INTELIGÊNCIA, 2018; PAIVA, 2016). No caso da EaD (Educação a Distância) em que os encontros presenciais são reduzidos, esta metodologia pode ser amplamente utilizada. Ao invés dos alunos de cursos na modalidade de EaD irem aos polos de apoio presencial para assistirem aulas (algumas vezes são aulas on-line, ministradas por professores por meio de videoconferência), os mesmos podem ir aos polos para encontrarem seus colegas e tutores, interagir e desenvolver a "lição de casa".

Nesta metodologia nem todas as aulas precisam ser ministradas de forma invertida. Podem ser intercaladas aulas mais comuns, tais como aulas expositivas para introduzir conteúdos e conceitos com as aulas "flippadas" (termo utilizado para denominar as aulas invertidas) (SCHMITZ, 2016).

Esta metodologia coloca o aluno como protagonista, ou seja, como sujeito ativo no processo de construção do conhecimento. Esta não é uma ideia nova, pois a participação mais ativa dos alunos nos processos de ensino e de aprendizagem faz parte da teoria construtivista de Piaget: o aluno como sujeito na construção do conhecimento (FRANCO, 1998).

Para tanto, o aluno precisa ter acesso prévio ao conteúdo, por meio de diferentes materiais didáticos, tais como videoaulas por exemplo. Estes materiais didáticos podem ser disponibilizados por meio de AVAs (Ambientes Virtuais de Aprendizagem), que facilitam o acesso dos alunos por meio da Internet (ESPÍNDOLA, 2016).

$\mathrm{O}$ docente precisa atuar como mediador entre o estudante e o conhecimento e não mais como apenas um expositor do conteúdo. O professor não precisa ser o detentor único do conhecimento, que passa a ser construído pelo grupo. Neste contexto, o aluno aprende de forma mais autônoma, aprende a aprender (SPITZCOVSKY, 2018). Devido à velocidade das informações, precisamos aprender todos os dias. Assim, aprender a aprender é um aspecto muito importante na sociedade do conhecimento.

Durante os horários presenciais das aulas, que efetivamente ocorrerão na instituição de ensino ou nos polos de apoio presencial (no caso da modalidade de EaD), os professores e/ou tutores podem trabalhar com projetos, experimentos, discussões, simulações, jogos, gamificação, estudos de caso ou com a resolução de problemas Aprendizagem Baseada em Problemas (ABP) ou Problem Based Learning (PBL), por exemplo. Os estudos de caso e outros exercícios e atividades podem ser desenvolvidos em grupo, estimulando que os alunos participem de grupos colaborativos (RAMAL, 2015).

Quando se trata de estudar programação de computadores, verifica-se que os processos de ensino e de aprendizagem de computação não são de conhecimento geral 
da população, já que estes conteúdos não são estudados no Ensino Básico e Fundamental. Quando os alunos ingressam no Ensino Superior, na área de Informática, os mesmos se deparam com a Lógica de Programação e chega-se a um momento crítico, gerando um alto índice de desistências. A lógica de programação, bem como o estudo de linguagens de programação, exige um esforço real e o nível de dificuldade empregado é alto. Estudar a área de programação de computadores é um dos requisitos fundamentais para os cursos de Computação (PEREIRA et al,. 2004 citados por SOUZA; SILVEIRA; PARREIRA, 2018).

Uma das metodologias que pode ser aplicada no ensino de programação é a ABP. Desta forma, os alunos são desafiados a resolver problemas, utilizando seus conhecimentos na área de lógica de programação. No Curso de Licenciatura em Computação da Universidade Federal de Santa Maria (UFSM), ministrado na modalidade de EaD no âmbito da Universidade Aberta do Brasil (UAB), esta metodologia é aplicada nas disciplinas da área e programação, tais como as de Introdução a Algoritmos e Linguagem de Programação I e II (PARREIRA et al., 2017).

Neste contexto, este artigo discute a relação entre a Sala de Aula Invertida, a Educação a Distância (EaD) e o ensino de programação de computadores por meio da metodologia da ABP.

\section{A Sala de Aula Invertida}

Na sala de aula invertida o tempo de aula presencial é mais curto do que o tradicional. Demo (2004) destaca que os professores precisam ministrar menos aulas, para que os alunos tenham mais oportunidade de estudar. Para este autor, uma aula, para ser boa, precisa ser curta. Entretanto, na sala de aula invertida, o trabalho do professor é maior, pois é preciso preparar os materiais didáticos e disponibilizá-los com antecedência (uma espécie de pré-aula no ensino presencial, ou a aula disponibilizada no AVA na modalidade de EaD). Entre os materiais didáticos, podem ser utilizadas videoulas. Estas videoaulas devem ser curtas, com tempo entre 5 e 8 minutos. Durante os vídeos, uma estratégia para estimular a interação é fazer perguntas aos alunos ou pedir que os mesmos façam anotações. Estas questões poderão ser abordadas, posteriormente, nos encontros presenciais (DIAS, 2017; UNIVERSIA BRASIL, 2017).

Para que esta metodologia funcione, os professores também precisam ser mais flexíveis quanto às expectativas e prazos estipulados para os alunos, ou seja, eles precisam de mais tempo para se dedicarem aos estudos e construírem o conhecimento. Neste sentido, pensando-se em um público de estudantes trabalhadores, o professor pode ficar se perguntando: como meus alunos irão se dedicar aos estudos se eles têm pouco tempo? Para resolver este problema pode-se utilizar o modelo in-flip, em que os alunos dedicam algum tempo na própria instituição de ensino para acessar os materiais didáticos produzidos e/ou selecionados pelo professor. Para os alunos que não conseguirem fazer as atividades da pré-aula, pode-se utilizar o modelo in-flip, com vídeos curtos. O professor, nesse caso, não deve ministrar o conteúdo da pré-aula nos encontros presenciais (LORENZONI, 2016).

Os processos de ensino e de aprendizagem, nesta metodologia, devem ser permeados por avaliações, para verificar se o aluno leu os materiais indicados (se ele fez a pré-aula), se é capaz de aplicar conceitos e se desenvolveu as competências esperadas. Com relação às competências, pode-se utilizar o modelo CHA - Competências 
VII Congresso Brasileiro de Informática na Educação (CBIE 2018)

Anais dos Workshops do VII Congresso Brasileiro de Informática na Educação (WCBIE 2018)

(conhecer), Habilidades (fazer) e Atitudes (ser). O conhecer pode ser avaliado de forma mais fácil (VILLAS-BÔAS, 2017).

Muitos autores destacam esta metodologia como inovadora mas será que é mesmo? Vygotsky (2007) já destacava em seus estudos a questão da interação social para estimular os processos de ensino e de aprendizagem (interação esta que deve ser estimulada e fortalecida nos encontros presenciais) (SUHR, 2016).

Entre os desafios encontram-se a motivação (como despertar a motivação dos estudantes, especialmente para fazerem as pré-aulas?), os hábitos de leitura e a qualidade da aprendizagem. Além da motivação, o professor precisa dispender mais tempo para dar feedbacks aos seus alunos e os processos de ensino e de aprendizagem precisam ser permeados por avaliações, visando identificar, entre outros aspectos: 1) se o aluno leu os materiais indicados (fez a pré-aula), 2) se o aluno é capaz de aplicar os conceitos estudados, 3) se o aluno consegue discutir os conteúdos com os colegas e 4) se o aluno consegue resolver os problemas propostos.

Como benefícios para os estudantes, destacam-se: autogestão, responsabilidade, autonomia e disposição para trabalhar em equipe.

Esta proposta tenta romper com o modelo de sala de aula tradicional, em que os alunos, de forma passiva, assistem às aulas expositivas, como meros receptores do conhecimento. Paulo Freire destacou que não temos que acabar com a escola, mas sim, mudá-la completamente até que nasça dela um novo ser tão atual quanto a tecnologia (MORAES; TERUYA, 2007).

Bergmann (2018) destaca a importância do dever de casa no contexto da sala de aula invertida. Segundo ele, os professores mandam os alunos para casa com tarefas para as quais eles não estão preparados para concluir. Na sala de aula invertida, as atividades mais complexas devem ser realizadas em sala de aula, com o apoio do professor, não em casa.

Bergmann (2018) coloca que, na sala de aula invertida, deve-se inverter a taxonomia proposta por Bloom, deixando o trabalho mais simples para ser feito em casa e o mais complexo para ser desenvolvido em sala de aula, por meio da interação com os colegas e com o professor ou tutor. A Figura 1 apresenta a Taxonomia de Bloom.

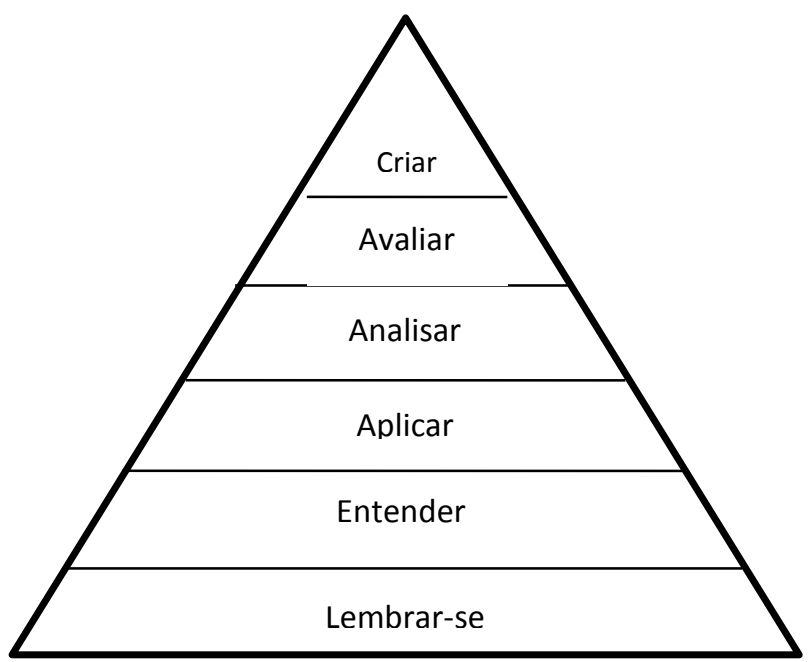

Figura 1 - Taxonomia de Bloom (Adaptada de Bergmann, 2018) 
De acordo com a Taxonomia de Bloom, a base da pirâmide envolve as atividades mais simples (lembrar-se, entender) e que podem ser realizadas em casa, no dever de casa invertido. À medida que se sobe nos níveis da pirâmide, o nível de dificuldade vai aumentando. Estas tarefas mais complexas (aplicar, analisar, avaliar e criar) devem ser realizadas em sala de aula ou nos encontros presenciais nos polos, no caso da EaD.

Bergmann (2018) destaca vantagens e desvantagens do dever de casa invertido, segundo pesquisas realizadas com alunos:

\section{Vantagens}

- a tarefa pode ser cumprida a qualquer horário do dia, já que os materiais didáticos (pré-aula) ficam disponíveis aos alunos. Se forem utilizados vídeos, os mesmos podem ser assistidos várias vezes, até mesmo por meio de smartphones;

- o aluno é estimulado a fazer perguntas sobre o dever de casa durante a aula ou, até mesmo, por meio de ferramentas no AVA;

- o dever de casa não é demorado;

- os alunos fazem as atividades mais difíceis em aula e é possível preparar as perguntas, com antecedência, para os professores;

- o dever de casa pode ser feito no ritmo e no tempo de cada aluno.

\section{Desvantagens}

- não é possível fazer perguntas durante o dever de casa (isto também acontece no dever de casa tradicional);

- se o aluno faz muitas disciplinas ao mesmo tempo, existem muitos materiais (pré-aulas) para ler e/ou assistir (vídeos);

- a velocidade baixa de acesso à Internet pode ser um empecilho para que os alunos acessem os materiais.

\section{Problem Based Learning}

A metodologia PBL (Problem Based Learning) ou ABP (Aprendizagem Baseada em Problemas) enfatiza o aprendizado autodirigido, centrado no estudante. Nesta metodologia, os estudantes devem trabalhar com o objetivo de solucionar um problema real ou simulado a partir de um contexto. Por meio desta metodologia, os processos de ensino e de aprendizagem são transformados em questões (problemas), permitindo que os alunos aprendam a resolver problemas relacionados ao seu futuro profissional.

Ao ensinar programação, na maioria das vezes, os professores partem de um enunciado na forma de um problema. A partir da decomposição do problema em passos é que se inicia o processo de aprendizado de programação. Tradicionalmente utiliza-se o ciclo entrada - processamento - saída para decompor o problema. A solução do problema (programa) pode ser escrita em linguagem natural ou na forma de pseudocódigo. O pseudocódigo pode ser escrito de acordo com a sintaxe de diferentes ambientes utilizados para o aprendizado de programação, tais como o Ambap - 
VII Congresso Brasileiro de Informática na Educação (CBIE 2018)

Anais dos Workshops do VII Congresso Brasileiro de Informática na Educação (WCBIE 2018)

Ambiente para o Aprendizado de Programação (AMBAP, 2018) e o VisuAlg. Utilizando um ambiente de programação, como é o caso do VisuAlg (APOIO INFORMÁTICA, 2018), o aluno pode testar, na prática, os algoritmos estudados. A utilização destes tipos de ambientes está baseada no ciclo experimentar-refletir-generalizar-testar proposto por Cowan (2002). O aluno, poderá construir um algoritmo e/ou programa, verificar os resultados apresentados por meio do VisuAlg e generalizar a solução, ou seja, pensar em um algoritmo que possa ser aplicado nos mais variados casos e validar esta generalização em outros problemas apresentados (PARREIRA et al., 2017). A metodologia da ABP é aplicada nas disciplinas que envolvem o estudo de programação de computadores no Curso de Licenciatura em Computação da UFSM/UAB.

\section{Considerações Finais}

A modalidade de EaD faz com que os alunos estudem de uma forma mais ativa. Sem a presença física dos professores e sem a interação presencial em sala de aula, os alunos atuam mais como sujeitos, construtores de seu próprio conhecimento. A EaD estimula os alunos a estudarem, de forma autônoma, auxiliando no processo de aprender a aprender. A EaD é definida como uma forma de ensino que possibilita a autoaprendizagem, com a mediação de recursos didáticos sistematicamente organizados, utilizados isoladamente ou combinados e veiculados por diversos meios de comunicação, tais como materiais impressos, materiais didáticos-digitais (ou virtuais), videoaulas, entre outros (MEDEIROS; FARIAS, 2003 citados por PEREIRA et al., 2017).

Com a elaboração de cursos na Internet o professor precisa modificar o seu papel. Em vez de ficar expondo conteúdos em sala de aula, cabe a ele, agora, conduzir os alunos ao processo de aprendizagem, instigando-os à pesquisa e ao desenvolvimento das atividades propostas em seus cursos. A mola principal para o bom andamento destes cursos é a motivação do aluno. O aluno deve ser estimulado a seguir as orientações propostas no curso apresentado. O processo de aprendizagem na $\mathrm{EaD}$ é baseado na abordagem construtivista (construtivismo), que vê o aluno como construtor do seu conhecimento (FRANCO, 1998), mas que está inserido em uma sociedade, em uma determinada cultura que contribuirá na determinação do seu saber (VYGOTSKY, 2007). Essa construção, que possibilita a aprendizagem, permite que os alunos assimilem novos conhecimentos, a partir de conceitos já conhecidos, envolvendo interação, estudo, experiência e erro.

Quanto à ABP, usando ambientes de simulação (tais como o Ambap e o VisuAlg, entre outros) ou ambientes de programação (IDE - Integrated Development Environment), tais como o NetBeans, os alunos podem construir o conhecimento a partir de problemas do mundo real, que podem ser solucionados de forma algorítmica. Assim, os alunos desenvolvem a lógica de programação, fundamental para os cursos da área de Computação e, também, para o profissional de Licenciatura em Computação, já que o contexto deste artigo envolve o Curso de Licenciatura em Computação da UFSM/UAB. O Licenciado em Computação, apesar de não necessariamente atuar profissionalmente como programador/desenvolvedor de software, precisa dos conhecimentos de programação para desenvolver softwares educacionais e/ou para ensinar lógica de programação nas escolas que já estão adotando este conteúdo em seus currículos. 
VII Congresso Brasileiro de Informática na Educação (CBIE 2018)

Anais dos Workshops do VII Congresso Brasileiro de Informática na Educação (WCBIE 2018)

A ABP baseia-se no estudo de problemas propostos, com a finalidade de fazer com que o aluno estude determinados conteúdos. Esta metodologia estimula uma atitude ativa do aluno em busca do conhecimento e não meramente informativa, como é o caso da prática pedagógica tradicional (SAKAI; LIMA, 1996 citados por BERBEL, 1998). A ABP, também, pode auxiliar o alunos a buscarem conhecimentos em sua memória, pois os problemas podem promover a elaboração de estruturas cognitivas que facilitam a recuperação de conhecimentos que podem ser utilizados na solução dos mesmos (RIBEIRO, 2005).

Quanto à possibilidade de ensinar programação de computadores na modalidade de EaD, no Curso de Licenciatura em Computação da UFSM/UAB, unimos os conceitos de Sala de Aula Invertida, EaD e ABP nas disciplinas de Introdução a Algoritmos e Linguagem de Programação I. Estas disciplinas são ofertadas, respectivamente, no $2^{\circ}$ e $3^{\circ}$ semestres do curso. Na disciplina de Introdução a Algoritmos estudam-se algoritmos e lógica de programação e os problemas são resolvidos com o apoio da ferramenta VisuAlg. Na disciplina de Linguagem de Programação I foi utilizada a linguagem de programação C e a IDE NetBeans. Além dos ambientes de programação, para que os alunos possam testar os programas desenvolvidos, as disciplinas utilizam materiais didáticos construídos por um grupo de docentes (professores conteudistas), na forma de $e$-book. Um destes materiais é o $e$-book de Introdução a Algoritmos (PARREIRA et al., 2017). Além dos e-books, os professores formadores utilizam o AVA Moodle e videoaulas no estilo tutorial (um passo-a-passo de como utilizar os ambientes de programação, demonstrando a solução de alguns problemas disponíveis nos e-books). O Curso de Licenciatura em Computação da UFSM/UAB é ministrado na modalidade de EaD, nos Polos localizados nas cidades de Cruz Alta, Palmeira das Missões, Sarandi, Seberi e Três Passos, todas no Estado do Rio Grande do Sul.

\section{Referências}

AMBAP. (2018). Ambiente para o Aprendizado de Programação. Disponível em: $<$ https://sites.google.com/site/ldsicufal/softwares/projeto-ambap>. Acesso em setembro, 2018.

APOIO INFORMÁTICA. (2018). VisuAlg. Disponível em: <http://www.apoioinformatica.inf.br/produtos/visualg>. Acesso em junho, 2018.

BERBEL, N. N. (1998) A problematização e a aprendizagem baseada em problemas: diferentes termos ou diferentes caminhos? Interface - Comunicação, Saúde, Educação. $\quad$ v.2, n.2. Disponível em: <https://www.scielosp.org/pdf/icse/1998.v2n2/139-154/pt>. Acesso em outubro, 2018.

BERGMANN, J. (2018). Aprendizagem Invertida para resolver o Problema do Dever de Casa. Porto Alegre: Penso.

COWAN, J. (2002). Como ser um Professor Universitário Inovador: reflexão na ação. Traduzido por Ronaldo Cataldo Costa. Porto Alegre: Artmed. 
VII Congresso Brasileiro de Informática na Educação (CBIE 2018)

Anais dos Workshops do VII Congresso Brasileiro de Informática na Educação (WCBIE 2018)

DEMO, P. (2004). Professor do futuro e reconstrução do conhecimento. 2. ed. Petrópolis, RJ: Vozes.

DIAS, M. M. (2017). Sala de Aula Invertida: 7 passos para preparar. Disponível em: $<$ http://ned.unifenas.br/blogtecnologiaeducacao/educacao/sala-de-aula-invertida-7passos-para-preparar/>. Acesso em abril, 2018.

ESCOLA DA INTELIGÊNCIA. (2018). Você sabe o que é a sala de aula invertida? Disponível em: <https://escoladainteligencia.com.br/voce-sabe-o-que-e-a-sala-deaula-invertida/>. Acesso em abril, 2018.

ESPÍNDOLA, R. (2016). Como funciona a sala de aula invertida? Disponível em: $<$ https://www.edools.com/sala-de-aula-invertida/>. Acesso em abril, 2018.

FRANCO, S. R. K. (1998). O Construtivismo e a Educação. Porto Alegre: Artes Médicas.

LORENZONI, M. (2016). Sala de Aula Invertida: o que muda no trabalho do professor? Disponível em: <http://info.geekie.com.br/sala-de-aula-invertida/>. Acesso em abril, 2018.

MORAES, S. A.; TERUYA, T. K. (2007). Paulo Freire e Formação do Professor na Sociedade Tecnológica. Simpósio Acadêmico UNIOESTE. Disponível em: <http://www.unioeste.br/cursos/cascavel/pedagogia/eventos/2007/Simp\%C3\%B3sio $\% 20$ Academico\%202007/Trabalhos\%20Completos/Trabalhos/PDF/64\%20Sonia\%2 0Algusta\%20de\%20Moraes.pdf>. Acesso em abril, 2018.

PAIVA, T. (2016). Como funciona a sala de aula invertida? Carta Educação. Disponível em: <http://www.cartaeducacao.com.br/reportagens/como-funciona-asala-de-aula-invertida/>. Acesso em abril, 2018.

PARREIRA, F.; SILVEIRA, S.; BERTOLINI, C.; SEVERO, R. (2017). Introdução a Algoritmos. Santa Maria: UFSM/NTE/UAB. Disponível em: <https://nte.ufsm.br/images/identidade_visual/introducaoalgoritmos.pdf $>$. Acesso em junho, 2018.

PEREIRA, A. S.; PARREIRA, F. J.; SILVEIRA, S. R.; BERTAGNOLLI, S. C. (2017). Metodologia da Aprendizagem em EaD. Santa Maria: UFSM/NTE/UAB. Disponível em: <https://nte.ufsm.br/images/identidade_visual/Metodologiaaprendizagem.pdf >. Acesso em junho, 2018.

RAMAL, A. (2015). Sala de Aula Invertida: a educação do futuro. Disponível em: <http://g1.globo.com/educacao/blog/andrea-ramal/post/sala-de-aula-invertidaeducacao-do-futuro.html>. Acesso em abril, 2018.

RIBEIRO, L. R. C. (2005). A Aprendizagem Baseada em Problemas (PBL): uma implementação na educação em engenharia na voz dos atores. Tese de Doutorado. São Paulo: UFSCar, Programa de Pós-Graduação em Educação. Disponível em: $<$ https://repositorio.ufscar.br/bitstream/handle/ufscar/2353/TeseLRCR.pdf?sequence =1\&isAllowed $=\mathrm{y}>$. Acesso em outubro, 2018.

SCHMITZ, E. X. S. (2016). Sala de Aula Invertida: uma abordagem para combinar metodologias ativas e engajar alunos no processo de ensino-aprendizagem. Disponível em: <https://nte.ufsm.br/images/PDF_Capacitacao/2016/RECURSO_EDUCACIONAL/ 
VII Congresso Brasileiro de Informática na Educação (CBIE 2018)

Anais dos Workshops do VII Congresso Brasileiro de Informática na Educação (WCBIE 2018)

Material_Didatico_Instrucional_Sala_de_Aula_Invertida.pdf $>$. Acesso em abril, 2018.

SOUZA, N. G.; SILVEIRA, S. R.; PARREIRA, F. J. (2018). Proposta de uma Metodologia para Apoiar os Processos de Ensino e de Aprendizagem de Lógica de Programação na Modalidade de Educação a Distância. Revista ECCOM, v.9, n.18. Disponível em: <http://fatea.br/seer3/index.php/ECCOM/article/view/851/856>. Acesso em junho, 2018.

SPITZCOVSKY, D. (2018). Conheça o novo conceito da Sala de Aula Invertida. Disponível em: <https://canaldoensino.com.br/blog/conheca-o-novo-conceito-dasala-de-aula-invertida $>$. Acesso em abril, 2018.

SUHR, I. R. F. (2016). Desafios no uso da Sala de Aula Invertida no Ensino Superior. Transmutare. Curitiba, v.1, n.1, p. 4-21, jan./jul. 2016. Disponível em: <https://periodicos.utfpr.edu.br/rtr/article/view/3872/2903>. Acesso em abril, 2018.

UNIVERSIA BRASIL. (2017). Os quatro pilares do aprendizado com sala de aula invertida. Disponível em: <http://noticias.universia.com.br/destaque/noticia/2017/06/27/1153743/4-pilaresaprendizado-sala-aula-invertida.html>. Acesso em abril, 2018.

VILLAS-BÔAS, M. A. (2017). Aulas Invertidas são muito mais Eficientes e Inclusivas. Disponível em: <https://www.cartacapital.com.br/blogs/vanguardas-doconhecimento/aulas-invertidas-sao-muito-mais-eficientes>. Acesso em abril, 2018.

VYGOTSKY, L. (2007) A Formação Social da Mente. 7. ed. São Paulo: Martins Fontes. 